\title{
Prevalence and antimicrobial susceptibility of methicillin- resistant Staphylococcus aureus clones: A study at Taksin Hospital, Bangkok, Thailand
}

\author{
Chanwit Tribuddharat ${ }^{\mathrm{a}}$, Chalermsri Pummangura ${ }^{\mathrm{b}}$, Maytinee Srifuengfung ${ }^{\mathrm{a}}$, Piyawan Pipobwatthana ${ }^{\mathrm{c}}$, \\ Huttaya Thuncharoon $^{\mathrm{c}}$, Vipavee Rodjun ${ }^{\mathrm{b}}$, Piriyaporn Chongtrakool ${ }^{\mathrm{a}}$, Somporn Srifuengfung ${ }^{\mathrm{b}, *}$ \\ a Faculty of Medicine Siriraj Hospital, Mahidol University, Bangkok 10700 Thailand \\ b Faculty of Pharmacy, Siam University, Bangkok 10160 Thailand \\ c Microbiology Laboratory, Taksin Hospital, Bangkok 10600 Thailand
}

*Corresponding author, e-mail: somporn.sri@mahidol.ac.th

ABSTRACT: Methicillin-resistant Staphylococcus aureus (MRSA) is a common pathogen in human diseases. Thirtyseven clinical clones from different patients were tested for a molecular study of the mecA gene and multilocus sequence types (ST). Total genomic extraction, followed by a polymerase chain reaction (PCR) for DNA amplification with specific primers for $m e c A$, and specific primers for various ST were used. Molecular typing for the study of genetic relationships among clones was performed by enterobacterial repetitive intergenic consensus (ERIC)-PCR. Antimicrobial susceptibility testing for all clones to 9 drugs was performed by the disk diffusion and vancomycin Etest. The presence of mecA was detected in all clones. The most common ST was MRSA-ST30, accounting for $81.1 \%$ of all MRSA tested, followed by MRSA-ST8/ST97/ST779 (8.1\%), MRSA-ST239 (2.7\%) and MRSA-nontypeable clones (8.1\%). Molecular typing by ERIC-PCR demonstrated DNA fingerprints with corresponding results with sequence types. All clones were susceptible (70-100\%) to fosfomycin, fusidic acid, gentamicin, tetracycline, trimethoprimsulfamethoxazole and vancomycin [minimal inhibitory concentration (MIC) range, $\mathrm{MIC}_{50}$ and $\mathrm{MIC}_{90}$ were $0.25-$ 1.0, 0.5 and $0.75 \mu \mathrm{g} / \mathrm{ml}$, respectively by using E-test] but resistant to ciprofloxacin, clindamycin and erythromycin. Inducible macrolide, lincosamide-type B streptogramin resistance (iMLSB) phenotype was 5.4\% while constitutive MLSB phenotype was 91.9\%. For MRSA-ST30 clones, 96.7\% were multi-drug resistant (MDR) with the most common pattern being resistant to ciprofloxacin, clindamycin and erythromycin. These results suggest the importance of MRSA in the field of epidemiology at a hospital in Thailand.

KEYWORDS: MRSA, Staphylococcus aureus, ST239, ST30, Thailand

\section{INTRODUCTION}

Methicillin-resistant Staphylococcus aureus (MRSA) is a pathogen that poses a serious threat to public health and hospital resources due to its resistance to several antimicrobial agents [1]. Its resistance is associated with the acquisition of a mobile genetic element called staphylococcal cassette chromosome mec that carries the mecA gene which encodes for the lowaffinity penicillin-binding protein $2 \mathrm{a}$ [2]. Infections caused by multidrug-resistant (MDR) clones lead to prolonged hospital stays and increased mortality. The spread of MRSA in hospitals is a serious health threat and a danger to the global economy [3]. MRSA is highly prevalent in hospitals worldwide with high rates $(>50 \%)$ reported in Asia, Malta, North America, and South America [4]. A review of 15 studies showed that between $13 \%$ and $74 \%$ of worldwide $S$. aureus infections were MRSA [5]. In Thailand, data from two-multi-center studies revealed MRSA prevalence of $57 \%$, with most cases being hospital-acquired MRSA [6]. At Thammasat University Hospital, Pathum Thani Province (adjacent to Bangkok) the prevalence of MRSA was reported to be $46 \%$ [7]. In a recent study, Chulalongkorn Memorial Hospital (a tertiary care uni- versity hospital in Bangkok) reported MRSA prevalence of $17 \%$ [8]. Two other provinces located outside Bangkok, Sa Kaeo Province (in eastern Thailand, near the Cambodian border) and Nakhon Phanom Province (in northeastern Thailand, near the border with Laos), reported MRSA prevalence of 10\% [9]. Hospitalacquired MRSA from 12 Asian countries from Saudi Arabia to Philippines was identified by multilocus sequence typing [10]. Due to the high frequency of MRSA in Asia, data from the region suggests that at least $90 \%$ of hospital-acquired MRSA accounts for $>$ $60 \%$ of MRSA in the world and can be traced to a single clone (ST239 or multilocus sequence type 239) [10-12]. The ST239 sequence has also been found in 26 countries outside Asia [12]. The global dissemination of ST239 is consistent with high transmissibility. ST239 evolved from DNA recombination involving the import of DNA from ST30 into ST8. However, ST239 has been recently replaced by other clones in several countries $[12,13]$. As for Thai MRSA, all four isolates tested in 2006 belonged to ST239 [11]. In 2008, $90 \%$ of MRSA, from northeast Thailand were linked to ST239 [12]. For other multilocus sequence types of MRSA, many studies have been conducted around the world. In 2019, a study from Northwestern China 
reported ST22 (2.02\%), ST59 (11.8\%) and ST239 (73.1\%) [14]. In 2018, a study from East China reported ST59 (77.67\%) [15]. Meanwhile in 2016, two Chinese hospitals in two different cities (Affiliated Hospital of Nantong University and Jiangsu Taizhou People's Hospital) of Jiangsu Province reported ST5 (12.9\%), ST7 (12.9\%) and ST398 (16.1\%) [16]. The aim of the present preliminary study was to determine the prevalence of sequence types and determine the current antibiogram profile of drug resistance in MRSA at Taksin Hospital.

\section{MATERIALS AND METHODS}

\section{Bacterial isolates}

Ethical approval for this study was obtained from the Human Research Committee of Siam University and the Bangkok Metropolitan Administration Human Research Ethics Committee with reference codes SIAMPYIRB 2020/007 and E009h/63_NA, respectively. The sample size was calculated to be 35 MRSA isolates using the statistics formula $n=Z^{2} \mathrm{P}(1-\mathrm{P}) / \mathrm{d}^{2}$, where $\mathrm{n}=$ number of clones, $\mathrm{Z}=1.96$ at $\alpha=0.05, \mathrm{P}=0.9$. (The latter was due to $90 \%$ prevalence of MRSA-ST239 in Thailand as mentioned in a previous report [12].) Therefore, 37 MRSA clones were randomly collected from 37 different patients to prevent duplicates of the same antibiogram profile at a tertiary-care hospital (Taksin Hospital, Bangkok, Thailand) over six months (Jan-Jun 2020). MRSA was isolated from various specimens and identified according to standard bacteriological methods [1]. If the specimen was sputum, it was accepted for culturing if it contained more than 25 polymorphonuclear cells and less than 25 squamous epithelial cells per low-power field $(10 \times 10$ magnification of microscope) [1]. The isolation and identification of MRSA was performed by standard techniques $[1,2]$. First, $S$. aureus was confirmed by using catalase and slide coagulase tests and if the result of a slide coagulase test was negative, a tube coagulase test was performed. Next, MRSA was confirmed using a disk diffusion test, according to CLSI. MRSA was defined if it was resistant to cefoxitin disk $(30 \mu \mathrm{g})$ [2].

\section{Antimicrobial susceptibility testing}

We carried out testing following the standard disk diffusion method [2] and E-test (BioMerieux, USA), according to the manufacturer's recommendation (vancomycin only). S. aureus ATCC 25923 was used as a control strain [2]. A clone was defined as multidrugresistant (MDR) if it was resistant to $\geqslant 3$ classes of drugs [17].

A D-test was performed to study the presence of inducible macrolide, lincosamide-type B streptogramins resistance (iMLSB) and constituted MLSB resistance. Erythromycin $(15 \mu \mathrm{g})$ and clindamycin $(15 \mu \mathrm{g})$ disks were placed $15 \mathrm{~mm}$ apart from edge to edge on a lawn of MRSA suspension with a turbidity equaling the
Table 1 Specimen and antimicrobial susceptibility by the disk diffusion method.

\begin{tabular}{|c|c|c|c|}
\hline Specimen & No. (\%) & Drug & No. (\%) \\
\hline Sputum & $24(64.9)$ & Ciprofloxacin & $2(5.4)$ \\
\hline Pus & 7 (18.9) & Clindamycin & $1(2.7)$ \\
\hline Urine & $3(8.1)$ & Erythromycin & $1(2.7)$ \\
\hline Blood & $2(5.4)$ & Fosfomycin & $26(70.3)$ \\
\hline Ascitic fluid & $1(2.7)$ & Fusidic acid & 37 (100) \\
\hline- & - & Gentamicin & 34 (91.9) \\
\hline Total & 37 (100) & Tetracycline & $32(86.5)$ \\
\hline & & SXT" & 35 (94.6) \\
\hline
\end{tabular}

Trimethoprim-sulfamethoxazole.

0.5 McFarland standard, which was spread on Mueller Hinton agar as previously described [2].

\section{Molecular study of $S$. aureus mecA and DNA sequence types}

DNA was extracted from MRSA colonies grown on blood agar containing 5\% sheep blood overnight at $35^{\circ} \mathrm{C}$ by the Gentra Puregene Yeast/Bacteria kit (QIAGEN) and was used as a template for PCR reactions. PCR amplification was performed by using $S$. aureus mecA specific primers (mecA-F, TGTCCGTAACCT GAATCAGC; mecA-R, TGCTATCCACCCTCAAACAG and PCR conditions as previously described [18]. The 863base pair (bp) amplicon was detected by $1 \%$ agarose gel-electrophoresis and ethidium bromide staining.

For identification of ST239 MRSA clones, PCR amplification was performed using primers ST8- and ST30-like sequences [(SA2003-F, CACTTTAAATACT GACGAAAAT; SA2003-R, TTGAAAATTGATCATTCAGC AA; 220 bp amplicon), and (SA0317-F, TCGCACTCT CGTTGAACA; SA0317-R, AAATCCGCTTCGACAAAC ATT; 484 bp) amplicon] and PCR conditions as previously described [12]. The PCR product size(s) of each ST was (were) as follows: 484 bp for ST-30; 220 bp for ST8/ST97/ST779; and 484 bp and 220 bp for ST-239.

In molecular typing for the study of genetic relationships among MRSA clones, enterobacterial repetitive intergenic consensus PCR (ERIC-PCR) was performed using primers (ERIC1R, ATGTAAGCTC CTGGGGATTCAC; ERIC2, AAGTAAGTGACTGGGGT GAGCG; random amplicon sizes) and PCR condition as previously described [19].

\section{Data analysis}

Data were entered and analyzed with SPSS Statistics version 20 (SPSS Inc, Chicago, IL, USA) for descriptive analysis. Discrete variables were expressed as percentages, mean, standard deviation and proportions.

\section{RESULTS}

In this study, there were $64.9 \%(24 / 37)$ male patients $(\mathrm{M}: \mathrm{F}=24: 13$; sex ratio $1.8: 1)$. The patient age ranged from 17-98, with a mean age and standard 


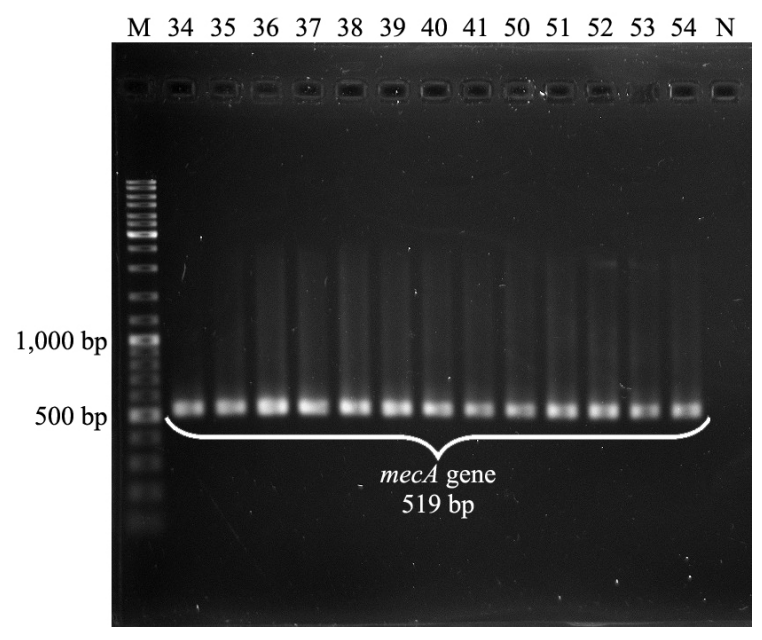

Fig. 1 PCR product of the mecA gene of some MRSA clones showed a size of 519 base pair products. Lane $\mathrm{M}$ is a $1 \mathrm{~kb}$ standard size marker. Lane $\mathrm{N}$ is a negative control.
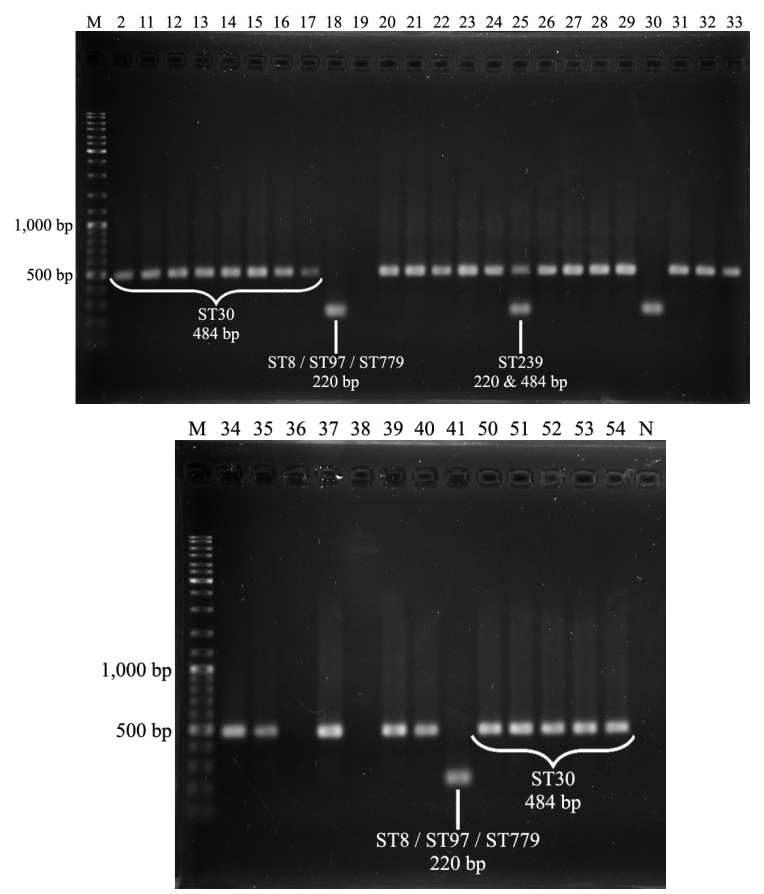

Fig. 2 Identification of methicillin-resistant $S$. aureus clones ST-30, ST8/ST97/ST779 and ST-239. Lane M is a $1 \mathrm{~kb}$ standard size marker. Lane $\mathrm{N}$ is a negative control.

deviation of $65 \pm 20.7$ years. The sources of clinical specimens were sputum $(24 / 37 ; 64.9 \%)$, pus $(7 / 37$; $18.9 \%$ ), urine $(3 / 37 ; 8.1 \%)$ (we found $10^{4}-10^{5}$ or $\left.>10^{5} \mathrm{CFU} / \mathrm{ml}\right)$, blood $(2 / 37 ; 5.4 \%)$, and ascitic fluid $(1 / 37 ; 2.7 \%)$ as shown in Table 1. MRSA clones were susceptible to fosfomycin (26/37; 70.3\%), fusidic acid (37/37; 100\%), gentamicin (34/37;
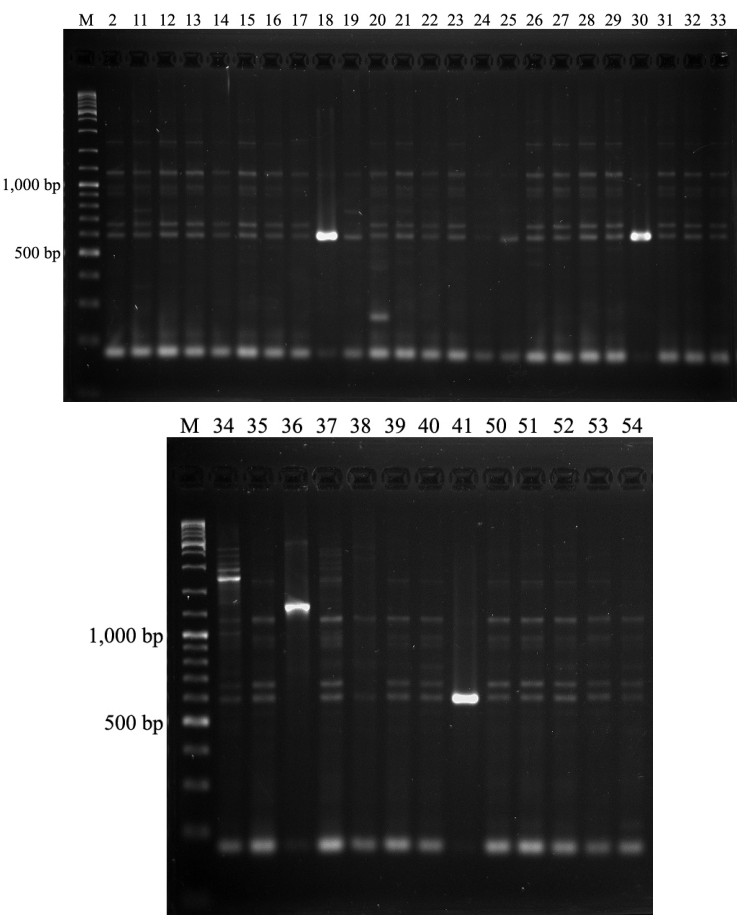

Fig. 3 The study of genetic relationship among MRSA clones by ERIC-PCR. Lane $\mathrm{M}$ is a $1 \mathrm{~kb}$ standard size marker.

Table 2 Multiple drug resistance (MDR) ${ }^{\#}$ of MRSA in this study.

\begin{tabular}{|c|c|c|c|}
\hline $\begin{array}{l}\text { DNA sequence } \\
\text { types }\end{array}$ & $\mathrm{n}(\%)$ & $\begin{array}{l}\text { No. of MDR } \\
\text { isolates }\end{array}$ & MDR pattern \\
\hline ST30 & $\begin{array}{l}30 / 37 \\
(81.1 \%)\end{array}$ & $\begin{array}{c}19 \mathrm{MDR} \\
9 \mathrm{MDR} \\
1 \mathrm{MDR} \\
1 \text { (Non-MDR) }\end{array}$ & $\begin{array}{l}\text { CIP CL ER } \\
\text { CIP CL ER FOS } \\
\text { CIP CL ER FOS TET } \\
\text { CIP (Non-MDR) }\end{array}$ \\
\hline ST8/ST97/ST779 & $\begin{array}{l}3 / 37 \\
(8.1 \%)\end{array}$ & $\begin{array}{l}1 \mathrm{MDR} \\
1 \mathrm{MDR} \\
1 \mathrm{MDR}\end{array}$ & $\begin{array}{l}\text { CIP CL ER FOS } \\
\text { CIP CL ER GEN } \\
\text { CIP CL ER GEN TET }\end{array}$ \\
\hline ST239 & $\begin{array}{l}1 / 37 \\
(2.7 \%)\end{array}$ & $1 \mathrm{MDR}$ & $\begin{array}{l}\text { CIP CL ER GEN SXT } \\
\text { TET }\end{array}$ \\
\hline ST-nontypeable & $\begin{array}{l}3 / 37 \\
(8.1 \%)\end{array}$ & $\begin{array}{c}1 \mathrm{MDR} \\
1 \mathrm{MDR} \\
1 \text { (Non-MDR) }\end{array}$ & $\begin{array}{l}\text { CIP CL ER SXT TET } \\
\text { CL ER TET } \\
\text { CL ER (Non-MDR) }\end{array}$ \\
\hline
\end{tabular}

\# Resistance $\geqslant 3$ classes of drugs; $\mathrm{n}=$ number of clones; CIP, ciprofloxacin; CL, clindamycin; ER, erythromycin; FOS, fosfomycin; GEN, gentamicin; SXT, trimethoprim/ sulfamethoxazole; TET, tetracycline.

$94.6 \%)$, tetracycline $(32 / 37 ; 86.5 \%)$, trimethoprimsulfamethoxazole $(35 / 37 ; 94.6 \%)$ and vancomycin (37/37; 100\%), but resistant to ciprofloxacin, clindamycin and erythromycin (susceptibility range 2.7$5.4 \%)$. Vancomycin's minimal inhibitory concentration (MIC) range, $\mathrm{MIC}_{50}$ and $\mathrm{MIC}_{90}$ values was $0.25-1.0$, 0.5 and $0.75 \mu \mathrm{g} / \mathrm{ml}$, respectively. 
All 37 randomly picked MRSA clones tested positive for mecA gene by PCR. Fig. 1 shows PCR products (519 base pairs) for the detection of mecA gene. For DNA sequence types, we found MRSA-ST30 (30/37; $81.1 \%$ ) to be predominant (Fig. 2) in many clinical specimens such as sputum, pus, urine, blood and ascitic fluid. For MRSA-(ST8/ST97/ST779), MRSAST239 and MRSA-nontypeable clones, we found these ST types less frequently $[(3 / 37 ; 8.1 \%),(1 / 37 ; 2.7 \%)$ and $(3 / 37 ; 8.1 \%)$, respectively]. The ST-nontypeable clones were not ST-30, ST8/ST97/ST779, and ST-239 and no further multilocus sequence typing was performed. The results of molecular typing to determine genetic relationship among MRSA clones done using the ERIC-PCR technique (Fig. 3) demonstrated DNA fingerprints corresponding to DNA sequence types.

For the D-test, inducible macrolide, lincosamidetype B streptogramins resistance (iMLSB) and constitutive MLSB was observed $(2 / 37 ; 5.4 \%$ and $34 / 37$; $91.9 \%$, respectively). One clone was susceptible to both erythromycin and clindamycin (1/37; 2.7\%). Two iMLSB clones were found in MRSA-ST30 and MRSA-ST nontypeable clones.

Table 2 shows that $96.7 \%$ (29/30) of MRSAST30 clones were multiple drug resistant (MDR). The most common pattern was resistance to three drugs, including ciprofloxacin, clindamycin and erythromycin (19 clones), followed by resistance to four drugs including ciprofloxacin, clindamycin, erythromycin and fosfomycin (9 clones). For MRSAST8/ST97/ST779, all three clones were MDR with three patterns (ciprofloxacin, clindamycin, erythromycin, fosfomycin; ciprofloxacin, clindamycin, erythromycin and gentamicin; and ciprofloxacin, clindamycin, erythromycin, gentamicin and tetracycline). There was one MRSA-ST239 clone, which was the most resistant MRSA in this study (resistance to six drugs: ciprofloxacin, clindamycin, erythromycin, gentamicin, trimethoprim-sulfamethoxazole and tetracycline). For MRSA-nontypeable, two clones were MDR with two patterns (ciprofloxacin, clindamycin, erythromycin, trimethoprim-sulfamethoxazole, tetracycline and clindamycin, erythromycin, tetracycline).

\section{DISCUSSION}

Most patients in this study were elderly, which is similar to a report from Shanghai, China between 2013-2018 in which patients' median age was 59 and age range was 7 months-97 years. In the same study, $67.5 \%$ of patients were male [20] which is close to our result of $64.9 \%$. Most patients in this study were in-patients and a few were out-patients. This investigation confirmed results of several other studies that MRSA is mostly isolated from clinical specimens of sputum, followed by pus, blood or urine $[8,21,22]$. The prevalence of MRSA was found mostly in sputum due to long hospitalizations and prolonged mechanical ventilation known for increased risk of nosocomial pneumonia. For the mecA gene study, there was an additional mecC gene, which also conferred methicillin resistance in $S$. aureus, but it was rare and less important than the mecA gene $[1,2,23]$. Vancomycin is still considered the drug of choice for treatment of MRSA infection. We did not find MRSA that was resistant to vancomycin in this study. However, vancomycin resistant $S$. aureus was reported recently [23]. On the other hand, a high number of vancomycin-resistant $E n$ terococcus faecium isolates carrying the vanA gene was found in patients of hospitals in northeastern Thailand, which also led to hospital-associated infections [24].

To the best of our knowledge, this is the first report of a decrease in predominant and international MRSAST239 clones, from $93 \%$ in 2008 in Thailand [12] to $2.7 \%$ in 2020 in a tertiary hospital in Bangkok. Interestingly, the disappearance of MRSA ST-239 in China was reported in 2018 [13]. Meanwhile, MRSA-ST30, is still found in many countries such as Argentina [25] and Paraguay [26].

We used the ERIC-PCR technique to track the spread of MRSA infection as previously reported $[27,28]$. This technique is rapid and inexpensive compared to multilocus sequence typing (MLST) or pulsed-field gel electrophoresis and hence reliable for epidemiological study in MRSA.

MRSA is a nosocomial bacterial pathogen and can also cause community-acquired infections [29]. Macrolide, lincosamide-type B streptogramin (MLSB) i.e. erythromycin and clindamycin are often used to treat skin and soft tissue infection caused by $S$. aureus. The inducible macrolide, lincosamide-type $B$ streptogramin resistance (iMLSB) (i.e., resistance to clindamycin) occurs when there is erythromycin that acts as an inducer of clindamycin resistance [30]. Antimicrobial susceptibility testing by the standard disk diffusion method may not be able to detect inducible clindamycin resistance. Therefore, treatment failure will occur if the D-test is not routinely performed in a clinical bacteriology laboratory. The iMLSB report from India in 2015 [31], Iran in 2020 [32] and Nepal in 2019 [30] was $11.8 \%, 21.7 \%$ and $43.8 \%$, respectively, which is higher than our result.

In an antimicrobial susceptibility test, the most common MDR pattern was resistance to ciprofloxacin, clindamycin and erythromycin (19 isolates) found in MRSA-ST30 clones. In a recent report in Poland, 92.9\% of MRSA clones were MDR and the most common pattern was resistance to ciprofloxacin, clindamycin, erythromycin and levofloxacin [33]. The clonal transmission of MDR-MRSA is usually spread by direct contact with an infected wound or from contaminated hands, usually those of healthcare providers. Also, people who carry MDR-MRSA but have no signs of infection (people who are colonized by this bacterium) may spread the bacteria to other people. 
There was a limitation of a small sample size and funding in this study. It would be useful to further investigate larger sample sizes and conduct a multicenter study. In conclusion, DNA sequence types and antibiogram profiles of drug resistance are useful and important epidemiological markers. These preliminary data should support ongoing studies by increasing the number of clinical MRSA isolates to improve the quality of epidemiological studies and surveillance of drug resistance.

Acknowledgements: This work was supported by the Siam University Council research grant number 002/03/2563. The authors thank Thanakorn Watcharasupat for molecular epidemiology testing.

\section{REFERENCES}

1. Becker K, Skov RL, von Eiff C (2015) Staphylococcus, Micrococcus, and other catalase-positive cocci. In: Jorgensen J, Pfaller M, Carroll K, Funke G, Landry M, Richter S, Warnock D (eds) Manual of Clinical Microbiology 11th edn, American Society for Microbiology Press, Washington DC, pp 354-382.

2. CLSI (2019) Performance standards for antimicrobial and susceptibility testing; twenty-ninth informational supplement. CLSI Document M100-S29, Wayne, PA.

3. Dadashi M, Nasiri MJ, Fallah F, Owlia P, Hajikhani B, Emaneini M, Mirpour M (2018) Methicillin-resistant Staphylococcus aureus (MRSA) in Iran: a systematic review and meta-analysis. $J$ Glob Antimicrob Resist 12, 96-103.

4. Stefani S, Chung DR, Lindsay JA, Friedrich AW, Kearns AM, Westh H, Mackenzie FM (2012) Methicillinresistant Staphylococcus aureus (MRSA): global epidemiology and harmonisation of typing methods. Int $J$ Antimicrob Agents 39, 273-282.

5. Kock R, Becker K, Cookson B, van Gemert-Pijnen JE, Harbarth S, Kluytmans J, Mielke M, Peters G, et al (2010) Methicillin-resistant Staphylococcus aureus (MRSA): burden of disease and control challenges in Europe. Euro Surveill 15, ID 19688.

6. Song JH, Hsueh PR, Chung DR, Ko KS, Kang CI, Peck KR, Yeom JS, Kim SW, et al (2011) Spread of methicillinresistant Staphylococcus aureus between the community and the hospitals in Asian countries: an ANSORP study. $J$ Antimicrob Chemother 66, 1061-1069.

7. Phokhaphan P, Tingpej P, Apisarnthanarak A, Kondo S (2017) Prevalence and antibiotic susceptibility of methicillin resistant Staphylococcus aureus, collected at Thammasat University Hospital, Thailand, August 2012-July 2015. Southeast Asian J Trop Med Public Health 48, 351-359.

8. Waitayangkoon P, Thongkam A, Benjamungkalarak T, Rachayon M, Thongthaisin A, Chatsawan T, Thammahong A, Chiewchengchol D (2020) Hospital epidemiology and antimicrobial susceptibility of isolated methicillin-resistant Staphylococcus aureus: a one-year retrospective study at a tertiary care center in Thailand. Pathog Glob Health 114, 212-217.

9. Jaganath D, Jorakate P, Makprasert S, Sangwichian O, Akarachotpong T, Thamthitiwat S, Khemla S, DeFries T, et al (2018) Staphylococcus aureus bacteremia incidence and methicillin resistance in rural Thailand, 2006-2014. Am J Trop Med Hyg 99, 155-163.

10. Ko KS, Lee JY, Suh JY, Oh WS, Peck KR, Lee NY, Song JH (2005) Distribution of major genotypes among methicillin-resistant Staphylococcus aureus clones in Asian countries. $J$ Clin Microbiol 43,421-426.

11. Chongtrakool P, Ito T, Ma XX, Kondo Y, Trakulsomboon S, Tiensasitorn C, Jamklang M, Chavalit T, et al (2006) Staphylococcal cassette chromosome mec (SCCmec) typing of methicillin resistant Staphylococcus aureus strains isolated in 11 Asian countries: a proposal for a new nomenclature for SCCmec elements. Antimicrob Agents Chemother 50, 1001-1012.

12. Feil EJ, Nickerson EK, Chantratita N, Wuthiekanun V, Srisomang P, Cousins R, Pan W, Zhang G, et al (2008) Rapid detection of the pandemic methicillin-resistant Staphylococcus aureus clone ST239, a dominant strain in Asian hospitals. $J$ Clin Microbiol 46, 1520-1522.

13. Dai Y, Liu J, Guo W, Meng H, Huang Q, Gao Q, Lv H, Liu Y, et al (2018) Decreasing methicillin-resistant Staphylococcus aureus (MRSA) infections is attributable to the disappearance of predominant MRSA ST239 clones, Shanghai, 2008-2017. Emerg Microbes Infect 8, 471-478.

14. Yuan W, Liu J, Zhan Y, Wang L, Jiang Y, Zhang Y (2019) Molecular typing revealed the emergence of $p v l$-positive sequence type 22 methicillin-susceptible Staphylococcus aureus in Urumqi, Northwestern China. Infect Drug Resist 12, 1719-1728.

15. Song Q, Wu J, Ruan P (2018) Predominance of community-associated sequence type 59 methicillinresistant Staphylococcus aureus in a paediatric intensive in care unit. $J$ Med Microbiol 67, 408-414.

16. Gu FF, Chen Y, Dong DP, Song Z, Guo XK, Ni YX, Han LZ (2016) Molecular epidemiology of Staphylococcus aureus among patients with skin and soft tissue infections in two Chinese Hospitals. Chin Med J 129, 2319-2324.

17. Seng R, Kitti T, Thummeepak R, Siriprayong A, Phukao T, Kongthai P, Jindayok T, Ketwong K, et al (2018) Antibiogram, antibiotic and disinfectant resistance genes, biofilm-producing and -associated genes, and genotype of methicillin-resistant Staphylococcus aureus clinical isolates from northern Thailand. Southeast Asian J Trop Med Public Health 49, 1060-1071.

18. Ishino K, Tsuchizaki N, Bok S, Kikuchi K, Totsuka K, Hotta K (2002) Relationship between aminoglycoside (AG) resistance and AG modifying enzyme gene profiles in MRSA. In: Abstract Book of the 10th International Symposium on Staphylococci and Staphylococcal Infections, Tsukuba, Japan, pp 149.

19. Versalovic J, Koeuth T, Lupski JR (1991) Distribution of repetitive DNA sequences in eubacteria and application to fingerprinting of bacterial genomes. Nucleic Acids Res 19, 6823-6831.

20. Gu F, He W, Xiao S, Wang S, Li X, Zeng Q, Ni Y, Han L (2020) Antimicrobial resistance and molecular epidemiology of Staphylococcus aureus causing bloodstream infections at Ruijin Hospital in Shanghai from 2013-2018. Sci Rep 10, ID 6019.

21. Mekviwattanawong S, Srifuengfung S, Chokepaibulkit K, Lohsiriwat D, Thamlikitkul V (2006) Epidemiology of Staphylococcus aureus infections and the prevalence of infection caused by community-acquired methicillin- 
resistant Staphylococcus aureus in hospitalized patients at Siriraj Hospital. J Med Assoc Thai 89, 106-117.

22. Suryatenggara AN, Khoeri MM, Waslia L, Tafroji W, Kunmalawati J, Subekti D, Safari D (2018) Identification and antibiotic susceptibility of methicillin-resistant Staphylococcus aureus strains collected at a referral Hospital, Jakata, Indonesia in 2013. Southeast Asian J Trop Med Public Health 49, 1053-1059.

23. Cong Y, Yang S, Rao X (2020) Vancomycin resistant Staphylococcus aureus infections: a review of case updating and clinical features. $J$ Adv Res 21, 169-176.

24. Panthasri P, Chaimanee P, Kenprom S, Kenprom P, Charoensri N, Chanawong A, Tavichakorntrakool R, Lulitanond A (2020) Evaluation of 3 (4, 5 dimethyl2-thiazolyl)-2, 5 diphenyl tetrazolium bromide method for rapid detection of vancomycin-resistant enterococci. ScienceAsia 46, 665-670.

25. Fernandez S, de Vedia L, Lopez-Furst MJ, Gardella N, Di Gregorio S, Ganaha MC, Prieto S, Carbone E, et al (2013) Methicillin-resistant Staphylococcus aureus ST30-SCCmec IVc clone as the major cause of community-acquired invasive infections in Argentina. Infect Genet Evol 14, 401-405.

26. Rodríguez F, Salinas C, Fernández S, Haim S, Mollerach M, Basualdo W, Castro H, Quiñónez B, et al (2020) Community-associated methicillin-resistant Staphylococcus aureus (CA-MRSA) clones from Paraguayan children. J Infect Dev Ctries 14, 290-297.

27. Candan ED, Idil N, Bilkay S (2013) Usefulness of REP and ERIC-PCR combination for tracking the spread of Staphylococcus aureus strains. Minerva Biotec 25, 245-250.

28. Abdollahi S, Ramazanzadeh R, Kalantar E, Zamoni S (2014) Molecular epidemiology of Staphylococcus aureus with ERIC-PCR method. Bull Env Pharmacol Life Sci 3, 158-165.

29. Lakhundi S, Zhang K (2018) Methicillin-resistant Staphylococcus aureus: molecular characterization, evolution, and epidemiology. Clin Microbiol Rev 31, e00020-18.

30. Shidiki A, Rajpandit B, Vyas A (2019) Characterization and prevalence of clindamycin resistance in Staphylococcus aureus from clinical specimens of national medical college and teaching hospital, Nepal. Asian J Pharm Clin Res 12, 90-92.

31. Mallikarjun K, Parameshwar S, Halesh LH, Siddesh KC (2015) Detection of inducible clindamycin resistance in Staphylococcus aureus and CONS at tertiary care hospital. Indian J Microbiol Res 2, 192-197.

32. Goudarzi H, Kobayashi N, Dadashi M, Pantucek R, Nasiri MJ, Fazeli M, Pouriran R, Goudazi H, et al (2020) Prevalence, genetic diversity, and temporary shifts of inducible clindamycin resistance Staphylococcus aureus clones in Tehran, Iran: A molecular-epidemiological analysis from 2013 to 2018. Front Microbiol 11, ID 663.

33. Kot B, Wierzchowska K, Piechota M, Gruzewska A (2020) Antimicrobial resistance patterns in methicillinresistant Staphylococcus aureus from patients hospitalized during 2015-2017 in hospitals in Poland. Med Princ Pract 29, 61-68. 